\title{
Analysis of an outbreak of variably methicillin-resistant Staphylococcus aureus with chromosomal RFLPs and $m e c$ region probes
}

\author{
P. R. STEWART, W. EL-ADHAMI, BARBARA INGLIS and J. CLARE FRANKLIN*
}

\begin{abstract}
Division of Biochemistry and Molecular Biology, Faculty of Science, Australian National University, Canberra ACT 2601 and *Department of Microbiology and Infectious Disease, Alfred Hospital, Prahran, Melbourne VIC 3181, Australia
\end{abstract}

\begin{abstract}
Summary. An outbreak of infections with multi-resistant Staphylococcus aureus with unusual methicillin resistance at a Melbourne hospital was investigated by examining restriction fragment length polymorphisms (RFLPs) of total DNA digested with the rare-cutting endonuclease SmaI. The polymorphisms were identified by pulsed-field gel electrophoresis (PFGE) and were analysed numerically to give quantitative estimates of genetic distances between isolates. The majority of the isolates were found to belong to one group, with only minor genetic differences between the isolates that showed varying resistance to methicillin, thereby suggesting development of resistant variants from one clonal type during the outbreak. These results were confirmed by DNA hybridisation analysis with specific resistance gene probes for parts of a multi-resistance gene cluster (including methicillin) in the chromosome. Analysis of the RFLP patterns of $S$. aureus isolates is potentially a useful procedure in clinical epidemiology.
\end{abstract}

\section{Introduction}

Considerable effort has been applied to the analysis of epidemics of methicillin-(or multi-) resistant Staphylococcus aureus (MRSA), including the tracking of human carriers and strains or lineages of the bacterium by means of molecular, biochemical, serological and phage-typing methods. ${ }^{1-4}$ While individual genetic or biological markers (e.g., phage-type, antibiotic resistance, plasmid carriage) may be associated with particular strains of MRSA involved in epidemics or outbreaks, it is not known whether particular clones of the organism are responsible for the initiation and development of outbreaks of infection, or whether any type of $S$. aureus present in an environment can take advantage of susceptible hosts and favourable circumstances to develop as a pathogen. The first proposal, referred to in its original form as the single MRSA clone hypothesis, ${ }^{5}$ has not been tested rigorously, since to do so requires a method that samples and compares the overall genetic similarity of strains isolated during an outbreak. A molecular method for genomic analysis and comparison of MRSA isolates has now been described ${ }^{6}$ which appears to meet these requirements. It relies on the detection in the DNA of isolates of restriction fragment length polymorphisms (RFLPs) generated by digestion with a rare-cutting

Received 20 May 1992; revised version accepted 14 Sept. 1992. Correspondence should be sent to Dr P. R. Stewart. endonuclease such as $S m a I$, and resolution of the resulting large genomic fragments by pulsed-field gel electrophoresis (PFGE). Its application to an outbreak of MRSA infection in Canberra hospitals in 1989 indicated that certain MRSA lineages have persisted in Australian hospitals since at least 1982, while others have arisen separately. ${ }^{6}$

The present paper describes the application of this method to a group of $S$. aureus strains with unusual methicillin-resistance characteristics which appeared at the Alfred Hospital in Melbourne. Isolates of this type test inconclusively with methicillin, giving an "intermediate" result rather than being clearly susceptible or resistant. Hyper-production of $\beta$-lactamase was not the cause of this borderline resistance. Such strains are referred to here as MISA (methicillinintermediate $S$. aureus). The RFLP method was used to make quantitative comparisons of genetic distances between isolates. In addition, genomic DNA was probed with cloned sequences from the mec (methicillin resistance) region of the chromosome to compare the organisation of the cluster of resistance genes normally resident here.

\section{Materials and methods}

\section{S. aureus isolates and standard strains}

Clinical isolates of bacteria were collected from different areas of the Alfred Hospital, Melbourne, as 
Table I. S. aureus isolates: epidemiological data

\begin{tabular}{|c|c|}
\hline Isolate & $\begin{array}{l}\text { Resistance; source; associated infections; } \\
\text { date isolated; phage-type }\end{array}$ \\
\hline \multicolumn{2}{|c|}{ MISA (multi-resistant with intermediate resistance to $M c$ ) } \\
\hline IBR & $\begin{array}{l}\mathrm{Mc}^{\mathrm{i}} \mathrm{Pc}^{\mathrm{r}} \mathrm{Em}^{\mathrm{r}} \mathrm{Su}^{\mathrm{r}} \mathrm{Tp}^{\mathrm{r}} \mathrm{Tc}^{\mathrm{r}} \mathrm{Gm}^{\mathrm{r}} \mathrm{Tb}^{\mathrm{r}} \text {; general medical } \\
\text { unit; abdominal abscess, sinus swabs, } \\
\text { sputum; Oct. } 1989 ; 85 / 90 / 88\end{array}$ \\
\hline IFR & $\begin{array}{l}\mathrm{Mc}^{\mathrm{P}} \mathrm{Pc}^{\mathrm{r}} \mathrm{Em}^{\mathrm{r}} \mathrm{Su}^{\mathrm{r}} \mathrm{Tp}^{\mathrm{r}} \mathrm{Tc}^{\mathrm{r}} \mathrm{Gm}^{\mathrm{r}} \mathrm{Tb}^{\mathrm{r}} ; \text { cardiothoracic } \\
\text { ICU; blood cultures, intravenous catheter, } \\
\text { sputum, throat swab; May } 1990 ; 90\end{array}$ \\
\hline IHA & 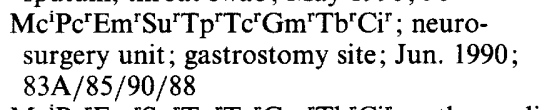 \\
\hline IMO & $\begin{array}{l}\mathrm{Mc}^{\mathrm{i}} \mathrm{Pc}^{\mathrm{r}} \mathrm{Em}^{\mathrm{r}} \mathrm{Su}^{\mathrm{r}} \mathrm{Tp}^{\mathrm{r}} \mathrm{Tc}^{\mathrm{r}} \mathrm{Gm}^{\mathrm{r}} \mathrm{Tb}^{\mathrm{r}} \mathrm{Ci}^{\mathrm{r}} ; \text {; } \text { orthopaedic } \\
\text { leg cellulitis; May } 1990 ; 83 \mathrm{~A} / 90\end{array}$ \\
\hline IPE & 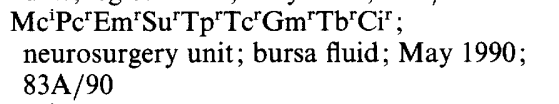 \\
\hline IRO & $\begin{array}{l}\mathrm{Mc}^{\mathrm{i}} \mathrm{Pc}^{\mathrm{r}} \mathrm{Em}^{\mathrm{r}} \mathrm{Su}^{\mathrm{r}} \mathrm{Tp}^{\mathrm{r}} \mathrm{Tc}^{\mathrm{r}} \mathrm{Gm}^{\mathrm{r}} \mathrm{Tb}^{\mathrm{r}} \mathrm{Ci}^{\mathrm{r}} \text {; general } \\
\text { medical unit; urine, sacral swab; Jul. 1990; } \\
\text { 83A/85/90/88 }\end{array}$ \\
\hline \multicolumn{2}{|c|}{ MRSA (multi-resistant with high resistance to $M c)$} \\
\hline RAN & 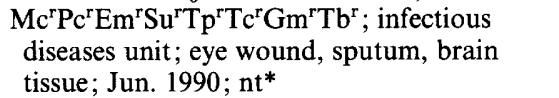 \\
\hline RBR & $\begin{array}{l}\mathrm{Mc}^{r} \mathrm{Pc}^{r} \mathrm{Em}^{\mathrm{r}} \mathrm{Su}^{\mathrm{r}} \mathrm{Tp}^{\mathrm{r}} \mathrm{Tc}^{\mathrm{r}} \mathrm{Gm}^{r} \mathrm{~Tb}^{\mathrm{r}} ; \mathrm{Mc}^{\mathrm{r}} \text { subclone } \\
\text { of IBR which appeared within zone of } \\
\text { inhibition around Mc disk (see IBR above); } \\
85 / 88\end{array}$ \\
\hline RMA & $\begin{array}{l}\mathrm{Mc}^{r} \mathrm{Pc}^{\mathrm{r}} \mathrm{Em}^{\mathrm{r}} \mathrm{Su}^{\mathrm{r}} \mathrm{Tp}^{\mathrm{r}} \mathrm{Tc}^{\mathrm{r}} \mathrm{Gm}^{\mathrm{r}} \mathrm{Tb}^{\mathrm{r}} ; \text { general surgery } \\
\text { ICU; sputum; Jun. } 1990 ; 52 \mathrm{~A} / 85 / 80\end{array}$ \\
\hline RNA & 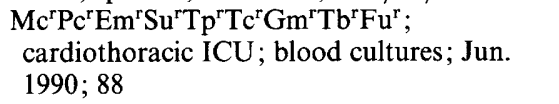 \\
\hline \multicolumn{2}{|c|}{ MSSA (Multi-resistant but sensitive to $M c)$} \\
\hline SHO & $\begin{array}{c}\mathrm{Pc}^{r} \mathrm{Em}^{\mathrm{r}} \mathrm{Su}^{\mathrm{r}} \mathrm{Tp}^{\mathrm{r}} \mathrm{Tc}^{\mathrm{r}} \mathrm{Gm}^{\mathrm{r}} \mathrm{Tb}^{\mathrm{r}} \mathrm{Fu} \mathrm{u}^{\mathrm{r}} \text {; general surgery } \\
\text { unit; intravenous catheter; Nov. 1990; nt }\end{array}$ \\
\hline SPO & 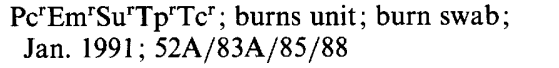 \\
\hline \multicolumn{2}{|c|}{ Miscellaneous isolates } \\
\hline ITA $\dagger$ & $\begin{array}{l}\mathrm{Pc}^{\mathrm{r}} ; \text { respiratory unit patient with cystic } \\
\text { fibrosis; sputum (several isolates); Jan. 1988, } \\
\text { Jan.-Nov. 1990, Mar.-Jun. 1991; 42E/47 }\end{array}$ \\
\hline $\mathrm{RBL}(\mathrm{Q}) \ddagger$ & $\begin{array}{l}\mathrm{Mc}^{\mathrm{r}} \mathrm{Pc}^{\mathrm{r}} \mathrm{Em}^{\mathrm{r}} \mathrm{Su}^{\mathrm{r}} \text {; Queensland isolate (not from } \\
\text { Alfred Hospital); 6/42E/47/75/84/81 }\end{array}$ \\
\hline \multicolumn{2}{|c|}{ Reference strains } \\
\hline ANS46 & $\begin{array}{l}\mathrm{Mc}^{r} \mathrm{Hg}^{\mathrm{r}} \mathrm{Tc}^{\mathrm{r}} \mathrm{Cd}^{\mathrm{r}} \mathrm{Km}^{\mathrm{r}} \mathrm{Cm}^{\mathrm{r}} \mathrm{Em}^{\mathrm{r}} \mathrm{Tp}^{\mathrm{r}} \mathrm{Sm}^{\mathrm{r}} \mathrm{Nv}^{\mathrm{r}} \mathrm{Rf}^{\mathrm{s}} \\
\mathrm{Vc}^{\mathrm{s}} ; \text { MRSA isolated at Royal } \\
\text { Melbourne Hospital; no other } \\
\text { epidemiological data available; } 1982 ; \\
\text { 83A/95/90 }\end{array}$ \\
\hline ANS62 & $\begin{array}{l}\mathrm{Mc}^{\mathrm{s}} \mathrm{Hg}^{5} \mathrm{Tc}^{\mathrm{s}} \mathrm{Cd}^{\mathrm{s}} \text { isogen of } \mathrm{ANS} 46 \text { generated by } \\
\text { acriffavine treatment } ;^{8} 83 \mathrm{~A} / 95 / 90\end{array}$ \\
\hline
\end{tabular}

$\mathrm{Cd}$, cadmium ion; $\mathrm{Ci}$, ciprofloxacin; $\mathrm{Cm}$, chloramphenicol; $\mathrm{Em}$, erythromycin; $\mathrm{Fu}$, fusidic acid; $\mathrm{Gm}$, gentamicin; $\mathrm{Hg}$, mercuric ion; $\mathrm{Km}$, kanamycin; Mc, methicillin; Nv, novobiocin; Pc, penicillin G; Rf, rifampicin; Sm, streptomycin; Su, sulphathiazole; Tb, tobramycin; Tc, tetracycline; $\mathrm{Tp}$, trimethoprim; Vc, vancomycin. Superscripts $\mathrm{i}, \mathrm{r}$ and $\mathrm{s}$ denote intermediate resistance, high-level resistance, and sensitivity, respectively, as defined in Materials and methods.

*Not typable with standard phage typing set at $100 \times$ RTD.

tSensitive to all antibiotics tested except Pc.

‡Unusual strain that was resistant to methicillin but sensitive to trimethoprim and tetracycline, of a type recently isolated in Queensland hospitals.

indicated in table I. In the nomenclature adopted for these isolates, the first letter (I, R or S) indicates the level of methicillin resistance (as described below), followed by two letters uniquely encoding the individual patient. Resistance phenotypes are expressed by the abbreviations listed in table I.
Strain ANS46 was a standard MRSA strain isolated originally at Royal Melbourne Hospital in 1982, and studied extensively since then. ${ }^{7-12}$ Strain ANS62 is a $\mathrm{Mc}^{\mathrm{s}}$ derivative of ANS46, generated by acriflavine treatment, from which the mec gene (which gives rise to $\mathrm{Mc}^{\mathrm{r}}$ ) and associated resistance genes (causing $\mathrm{Hg}^{\mathrm{r}}$, $\mathrm{Tc}^{\mathrm{r}}, \mathrm{Cd}^{\mathrm{r}}$ ) have been lost because of deletion of $41 \mathrm{~kb}$ of the chromosome. ${ }^{11,12}$ Canberra type-I and Canberra type-II strains are representative strains from an MRSA outbreak in Canberra hospitals in $1989 .{ }^{6}$

\section{Antibiotic susceptibility testing}

Agar dilution susceptibility tests ${ }^{13}$ were performed with the antibiotics indicated in table I with IsoSensitest Agar (Oxoid). Resistance to methicillin was measured at antibiotic concentrations of 4 and $8 \mathrm{mg} / \mathrm{L}$, with an inoculum of $c .10^{7} \mathrm{cfu} / \mathrm{spot}$ and overnight incubation at $30^{\circ} \mathrm{C}$. MICs for methicillin and oxacillin were determined by microdilution tests in IsoSensitest Broth (Oxoid), with inoculum sizes of $10^{4}-10^{7}$ cells $/ \mathrm{ml}$ to test the effect of inoculum size on the MIC, and incubation overnight at $30^{\circ} \mathrm{C}$.

Resistance to antimicrobial agents encoded in the mec region of the chromosome was measured by a disk diffusion test ${ }^{7}$ on Tryptone Soya Agar (Oxoid) with disks containing(/disk): Mc $100 \mu \mathrm{g} ; \mathrm{Hg}$ (mercuric chloride) $100 \mu \mathrm{g}$; Cd (cadmium chloride) $250 \mu \mathrm{g}$; and Tc $100 \mu \mathrm{g}$. Plates were incubated at $37^{\circ} \mathrm{C}$ for $24 \mathrm{~h}$ or at $30^{\circ} \mathrm{C}$ for $48 \mathrm{~h}$ before measuring zones of inhibition.

\section{Preparation of cells and digestion of genomic DNA}

Cells were suspended in agarose plugs and cell walls were digested in situ with lysozyme and lysostaphin, as described by Inglis et al. ${ }^{11}$ After proteolytic removal of residual protein with proteinase $\mathrm{K}$ and SDS, the intact genomic DNA was cleaved with $S m a I$, a rare-cutting restriction endonuclease (recognition site 5'CCCGGG-3') which cleaves the $S$. aureus chromosome into c. 20 fragments. ${ }^{11,14}$

\section{Pulsed-field gel electrophoresis (PFGE)}

The digested plugs were inserted into wells in agarose $1 \%$ gels $(12.5 \mathrm{~cm} \times 14 \mathrm{~cm})$, and PFGE was performed at $200 \mathrm{~V}$ for $27 \mathrm{~h}$ at $12-14^{\circ} \mathrm{C}$ in a BioRad CHEF apparatus with Tris-borate buffer $(45 \mathrm{~mm}$ Tris, $45 \mathrm{~mm}$ boric acid, $1 \mathrm{~mm}$ EDTA, pH 8.3). Electrode switching was as follows: single ramp; initial forward time of $1 \mathrm{~s}$; final forward time of $40 \mathrm{~s}^{15}$ When electrophoresis was complete, gels were stained for $1 \mathrm{~h}$ with ethidium bromide $(0.5 \mathrm{mg} / \mathrm{L}$ in water $)$, destained in water for 2-6 h, and photographed with UV transillumination.

\section{Analysis of DNA fragment patterns on PFGE gels}

DNA fragment alignments were determined for samples run on the same gels, with common and 


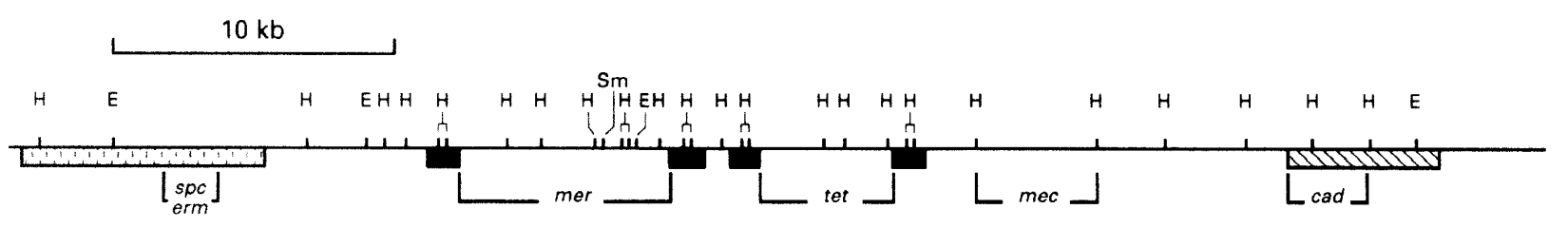

MA13

Fig. 1. Map of the mec region in strain ANS46. Letters indicate endonuclease sites; shaded blocks show positions of insertion sequence IS257; hatched blocks show Tn554 (left) and $\psi \mathrm{Tn} 554$ (right); and bracketed regions show genes for resistance to spectinomycin(spc), macrolides, lincosamides and streptogramin B (erm), mercuric ion $(\mathrm{mer})$, tetracycline $(t e t)$, methicillin $(\mathrm{mec})$, and cadmium ion $(\mathrm{cad})$. Cloned fragments used as probes are identified below the map. The endonuclease sites shown are: H, HindIII; E, EcoRI; and Sm, SmaI.

different fragments identified pairwise for all isolates, as described previously. ${ }^{6}$ Values of $p$, the estimate of genetic distance (fraction of nucleotides different between pairs of isolates), were calculated with numerical methods described previously. ${ }^{16,17}$ A matrix of $p$ values for all pairwise comparisons of DNA from each isolate was constructed, from which clusters were generated by single linkage analysis, and fused by triangle overlap within clusters. ${ }^{18}$

\section{Hybridisation analysis}

DNA fragments resolved in agarose gels by PFGE were transferred to nitrocellulose filters by Southern blotting, after which the filters were probed with methods described previously. ${ }^{8}$ Three fragments of DNA cloned from the mec region of ANS46, ${ }^{8.11}$ which carries determinants for $\mathrm{Em}^{\mathrm{r}}, \mathrm{Sp}^{\mathrm{r}}, \mathrm{Hg}^{\mathrm{r}}, \mathrm{Tc}^{\mathrm{r}}$ and $\mathrm{Cd}^{\mathrm{r}}$ as well as $\mathrm{Mc}^{r}$. were used as probes (fig. 1): (i) MA13, from the left end of the multi-resistance cluster (MA13 also hybridises with two copies of Tn554 located elsewhere in the chromosome of ANS46) $;^{19}$ (ii) MA11, which identifies fragments carrying the mec gene itself; and (iii) MA14, which identifies the right end of the cluster. $^{12}$

\section{Results}

\section{Measurement of resistance in isolates}

Agar dilution tests differentiated between methicillin-sensitive, -resistant, and -intermediate types. Sensitive isolates (MSSA) were inhibited by $4 \mathrm{mg} / \mathrm{L}$, resistant isolates (MRSA) were not inhibited by $8 \mathrm{mg} / \mathrm{L}$, and intermediate isolates (MISA) were inhibited by 8 but not by $4 \mathrm{mg} / \mathrm{L}$. Broth dilution tests revealed that methicillin and oxacillin MICs for MSSA and MRSA isolates $(0.5 \mathrm{mg} / \mathrm{L}$ and $>32 \mathrm{mg} / \mathrm{L}$, respectively) were relatively unaffected by inoculum size. However. MISA isolates showed considerable variation in MIC values of methicillin $(2-16 \mathrm{mg} / \mathrm{L})$ and oxacillin $(8->32 \mathrm{mg} / \mathrm{L})$, the MIC value being greater with larger inocula.

The disk diffusion method used to detect resistance to antimicrobial agents encoded in the mec region $(\mathrm{Cd}$, $\mathrm{Hg}, \mathrm{Mc}$ and $\mathrm{Tc}$ ), does not detect intermediate resistance to Mc as described for the agar dilution method. MISA isolates had zones of inhibition typically $34-36 \mathrm{~mm}$ in diameter at $37^{\circ} \mathrm{C}$, whereas strain ANS62 (which has mec region genes deleted) and strain ANS46 (mec region intact) had zones of inhibition of $38 \mathrm{~mm}$ and $21 \mathrm{~mm}$, respectively. Other MRSA isolates used in this study had zones of 12-22 mm. For the MRSA isolates and strain ANS46, these zone sizes were influenced strongly by temperature, decreasing to $0-9 \mathrm{~mm}$ at $30^{\circ} \mathrm{C}$; strain ANS62 and the MISA isolates showed negligible changes in zone diameter when incubated at $30^{\circ} \mathrm{C}$.

Strain RBR was not a primary clinical isolate, but was picked off a plate of strain IBR as a colony growing within the zone of inhibition of a methicillin disk. Strain RBR had MIC and disk inhibition values similar to those of the other MRSA isolates examined.

\section{Epidemiology}

All isolates tested were multi-resistant to antibiotics, with the exception of strain ITA which was only $\mathrm{Pc}^{\mathrm{r}}$ and had intermediate resistance to methicillin; strains ITA and RBL(Q) were included in this analysis as control isolates likely to be unrelated epidemiologically to the other $S$. aureus isolates included in the study.

Of the seven MISA isolates, all but strains IBR and ITA appeared as a small outbreak lasting $c .2$ months in mid-1990; strain IBR was identified $>6$ months previously. The outbreak isolates came from a range of physically separate wards and units, and from different types of infections. Four different phagetyping patterns were represented within the outbreak group.

\section{$P F G E$ of $D N A$ from the isolates}

Gels stained with ethidium bromide showing the fragment patterns (RFLPs) generated by Smal digestion of genomic DNA from each strain or isolate are shown in fig. 2. Fragment sizes were in the range $c$. 


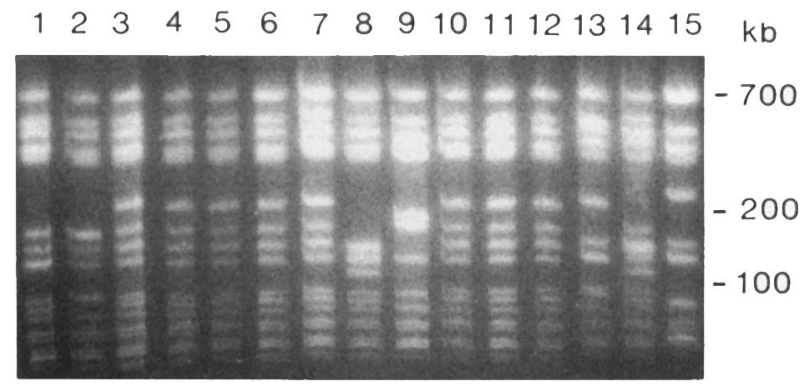

Fig. 2. PFGE of genomic DNA, digested with SmaI and stained with ethidium bromide, from clinical isolates SPO (track 1), SHO (2), IMO (3), IPE (4), IHA (5), IRO (6), IFR (7), ITA (9), IBR (10), RBR (11), RMA (12), RAN (13), RNA (14), RBL(Q) (15), and strain ANS46 (8). Size markers, derived from comparison of ANS46 fragments with $\lambda$ concatemers in previous work, ${ }^{11}$ are shown on the right of the figure.

7-700 kb. A general similarity of the RFLP patterns within the MRSA and MISA groups was observed, indicating that the SmaI sites were similar in number and location within the genome of isolates from these two groups, and thus that there was similarity of sequence throughout the genome.

A quantitative estimate of the extent of genomic similarity was obtained by counting the number of DNA fragments common to pairs of isolates, and calculating $p$, an estimate of the fraction of nucleotides different for that pair. A matrix of relationships between isolates was thus generated, from which a dendrogram summarising the relationships of all isolates was constructed (fig. 3). This showed that four of the five outbreak MISA isolates could not be separated (strains IHA, IMO, IPE and IRO), and that, with the exceptions of strains ITA, RBL(Q), RAN, RNA and ANS46/62, there was a general clustering of related types; this cluster will hereafter be referred to as the Alfred group. Strains RNA and RAN formed a loose cluster with strain ANS46/62, and the inde- pendently isolated strains ITA and RBL(Q) had a distant relationship to each other and to the other isolates, both on epidemiological grounds (table I) and on the basis of RFLPs.

\section{Arrangements of genes in the mec region of the chromosome of the isolates}

Phenotypic testing of isolates for resistance genes known to map in the $m e c$ cluster $^{8,9}$ showed variation among the isolates (table II). In contrast to strains ANS46 and RNA, none of the MISA or MRSA isolates of the Alfred group were $\mathrm{Hg}^{\mathrm{r}}$ or $\mathrm{Tc}^{\mathrm{r}}$ by disk sensitivity testing. It should be noted that this type of sensitivity testing gives a different outcome to agar dilution tests; thus, all isolates except strains ITA and $\mathrm{RBL}(\mathrm{Q})$ were resistant to $\mathrm{Tc} 5 \mathrm{mg} / \mathrm{L}$ in agar, and are recorded as $\mathrm{Tc}^{\mathrm{r}}$ in table $\mathrm{I}$. This low-level resistance is thought to result from a tet gene located elsewhere in the chromosome. ${ }^{14}$ Additional resistance is generated by an integrated copy of the $\mathrm{Tc}^{\mathrm{r}}$ plasmid $\mathrm{pT} 181$ in the $m e c$ region of strains such as ANS46. ${ }^{8}$

The results of hybridisation experiments are shown in fig. 4. Strain ANS46 contained one fragment $(145 \mathrm{~kb})$ that hybridised with probes MA11 and MA14, and three fragments that hybridised with probe MA13-a 110-kb fragment carrying part of the mec region, and two other fragments $(410$ and $650 \mathrm{~kb})$ which carry an additional copy of Tn 554 . Isolate RNA showed the same pattern of hybridisation. The Alfred group of MRSA and MISA isolates had one fragment $(220 \mathrm{~kb})$ that hybridised with probes MA11 and MA14, and two fragments (410 and $650 \mathrm{~kb}$ ) that hybridised with probe MA13. The MSSA isolates of the Alfred group showed hybridisation only between the 410 - and $650-\mathrm{kb}$ fragments and probe MA13. Isolate RAN had the same pattern of hybridisation as the Alfred group. The two miscellaneous isolates

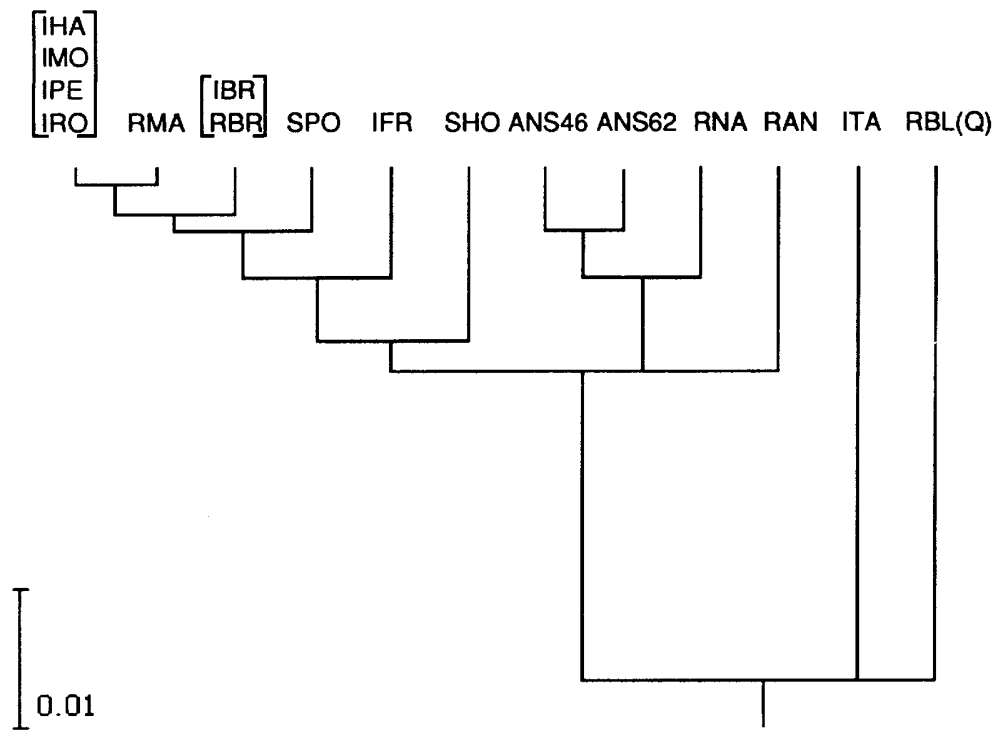

Fig. 3. Dendrogram calculated from the $p$ values for genomic DNA of the isolates after RFLP analysis. The genetic distance ( $p$ ) is represented by the vertical distance between isolates. $\mathrm{Bar}=p$ value 0.01 . 
Table II. Presence in S. aureus isolates of resistance determinants from the mec region of the chromosome

\begin{tabular}{|c|c|c|c|c|}
\hline \multirow{2}{*}{ Isolate } & \multicolumn{4}{|c|}{ Resistance* } \\
\hline & $\mathrm{Hg}$ & $\mathrm{Tc}$ & Mc & $\mathrm{Cd}$ \\
\hline \multicolumn{5}{|l|}{$M I S A$} \\
\hline IBR & $\mathbf{s}$ & $\mathbf{s}$ & $\mathbf{s}$ & $\mathbf{r}$ \\
\hline IFR & $\mathbf{s}$ & $\mathbf{s}$ & $\mathbf{s}$ & $\mathrm{r}$ \\
\hline IHA & s & $\mathbf{s}$ & $\mathbf{s}$ & $\mathbf{r}$ \\
\hline IMO & s & s & s & $\mathbf{r}$ \\
\hline IPE & s & $\mathbf{s}$ & s & $\mathbf{r}$ \\
\hline IRO & s & s & s & $\mathbf{r}$ \\
\hline \multicolumn{5}{|l|}{$M R S A$} \\
\hline RAN & $\mathbf{s}$ & $\mathbf{s}$ & r† & $\mathbf{r}$ \\
\hline RBR & s & s & $\mathrm{r} \dagger$ & $r$ \\
\hline RMA & $\mathbf{s}$ & $\mathbf{s}$ & $\mathrm{r} \dagger$ & $\mathbf{r}$ \\
\hline RNA & $\mathbf{r}$ & $\mathrm{r}$ & $\mathrm{r} \dagger$ & $\mathbf{r}$ \\
\hline \multicolumn{5}{|l|}{$M S S A$} \\
\hline SHO & $\mathbf{s}$ & $\mathrm{i}$ & 3 & $\mathbf{s}$ \\
\hline SPO & $\mathbf{s}$ & $\mathbf{s}$ & $\mathbf{s}$ & $\mathbf{s}$ \\
\hline \multicolumn{5}{|c|}{ Miscellaneous isolates } \\
\hline ITA & s & $\mathbf{s}$ & $\mathbf{s}$ & $r$ \\
\hline RBL(Q) & $\mathbf{r}$ & $\mathbf{s}$ & $\mathrm{r} \dagger$ & $\mathbf{r}$ \\
\hline \multicolumn{5}{|c|}{ Reference strains } \\
\hline ANS46 & $\mathbf{r}$ & $\mathbf{r}$ & $\mathbf{r}$ & $r$ \\
\hline ANS62 & $\mathbf{s}$ & $\mathbf{s}$ & $\mathbf{s}$ & $\mathbf{s}$ \\
\hline
\end{tabular}

*Antimicrobial agents indicated are those for which resistance gene are clustered in the mec region of strain ANS46, and deleted from strain ANS62; s indicates sensitivity equal to or greater than that of ANS62, $r$ indicates resistance equal to or greater than that of ANS46, and $i$ indicates resistance intermediate between these by disk diffusion tests (this method of testing does not demonstrate intermediate levels of methicillin resistance).

$\dagger$ Resistance heterogeneity, detected as individual colonies growing within the zone of inhibition.

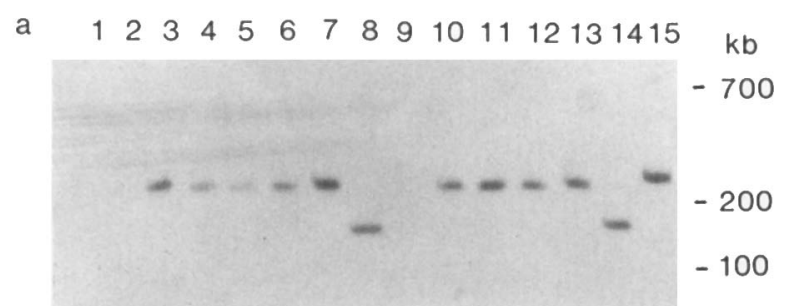

b $\quad \begin{array}{lllllllllllllll}1 & 2 & 3 & 4 & 5 & 6 & 7 & 8 & 9 & 10 & 11 & 12 & 13 & 14 & 15\end{array}$
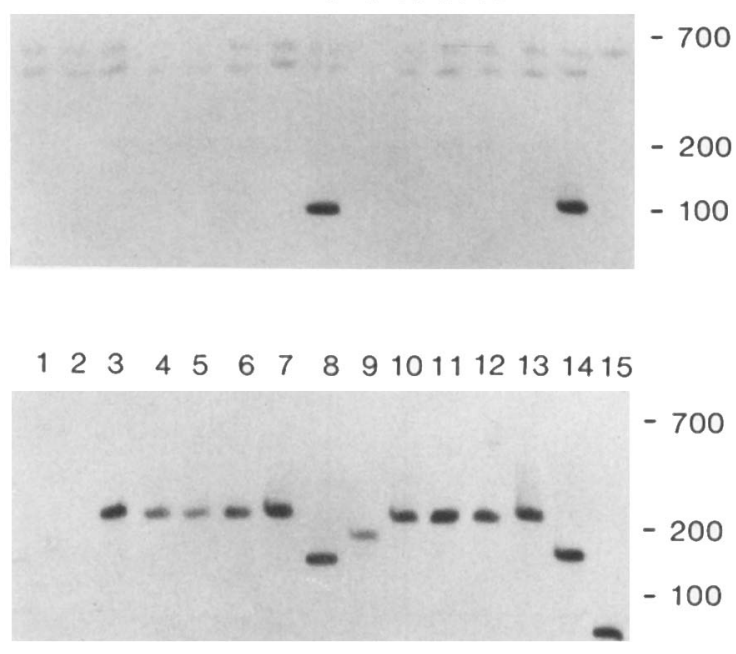

Fig. 4. DNA from the gel shown in fig. 2 after transfer to nitrocellulose filters and hybridisation with probes: (a) MA11; (b) MA13; and (c) MA14.

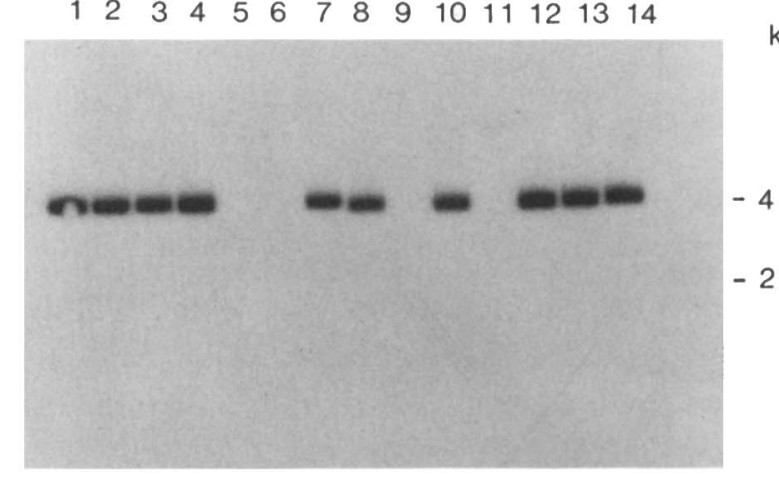

b

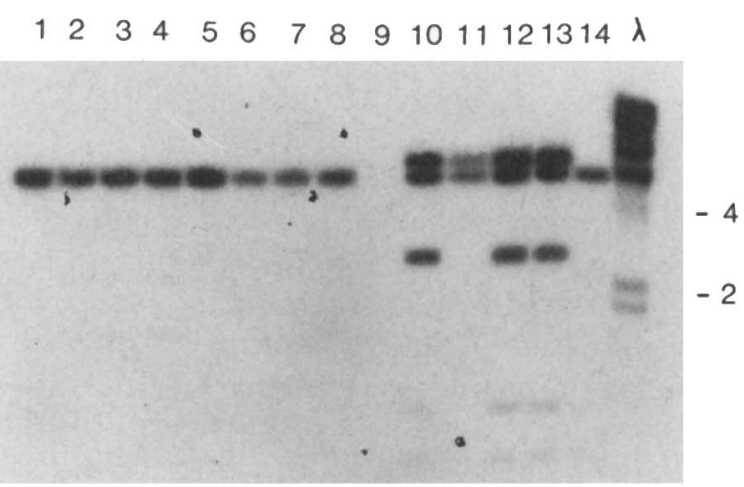

C

$\begin{array}{llllllllllll}1 & 2 & 3 & 4 & 5 & 6 & 7 & 8 & 9 & 10 & 11121314 & \lambda\end{array}$

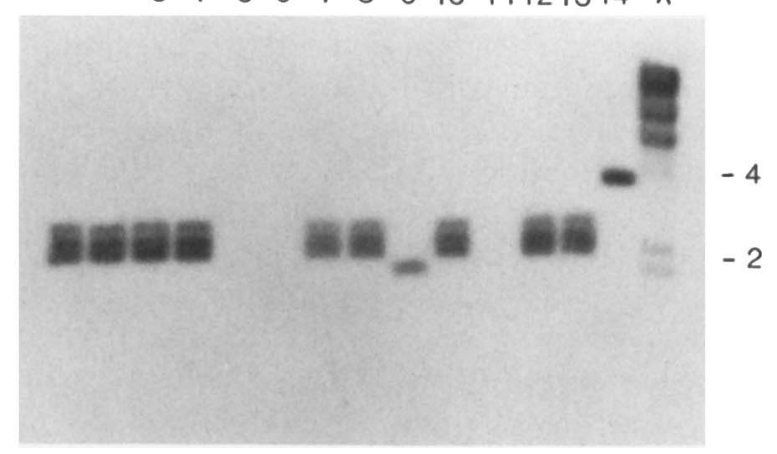

Fig. 5. DNA from the isolates indicated was digested with HindIII, electrophoresed under constant field conditions, transferred to nitrocellulose, and hybridised with probes: (a) MA11; (b) MA13; and (c) MA14. Isolates were: RMA (track 1); IBR (2); IMO (3); IFR (4); SPO (5); SHO (6); Canberra Type-II (7); RAN (8); ITA (9); Canberra Type-I (10); RNA (13); RBL(Q) (14); strains ANS46 (12); and ANS62 (11). Molecular size markers from $\lambda$ DNA digested with HindIII are shown on the right hand side.

showed quite different patterns. Strain RBL(Q) had one fragment $(650 \mathrm{~kb})$ that hybridised with probe MA13, and additional fragments that hybridised with probes MA11 $(240 \mathrm{~kb})$ and MA14 $(80 \mathrm{~kb})$. Isolate ITA hybridised only with probe MA14.

For more detailed comparisons, DNA from the isolates was digested with HindIII (which cuts staphylococcal DNA into at least several hundred fragments), electrophoresed, transferred to filters and hybridised with the same three probes. The results are shown in fig. 5, and a summary of the data is given in table III. The significant features were as follows. The MRSA and MISA isolates of the Alfred group were 
Table III. SmaI and HindIII fragments of DNA from different isolates that hybridised with DNA probes for the mec region of the chromosome

\begin{tabular}{|c|c|c|c|c|c|c|}
\hline \multirow{2}{*}{$\begin{array}{l}\text { Strain or } \\
\text { isolate }\end{array}$} & \multicolumn{3}{|c|}{$\begin{array}{l}\text { SmaI fragments (kb) } \\
\text { hybridising with }\end{array}$} & \multicolumn{3}{|c|}{$\begin{array}{l}\text { HindIII fragments }(\mathrm{kb}) \\
\text { hybridising with }\end{array}$} \\
\hline & MA11 & MA13 & MA14 & MA11 & MA13 & MA14 \\
\hline ANS46 & 145 & $110,410,650$ & 145 & 4 & $0 \cdot 7,0 \cdot 9,2 \cdot 7,7,8 \dagger$ & $2 \cdot 2,2 \cdot 4,2 \cdot 5$ \\
\hline RNA & 145 & $110,410,650$ & 145 & 4 & $0 \cdot 7,0 \cdot 9,2 \cdot 7,7,8 \dagger$ & $2 \cdot 2,2 \cdot 4,2 \cdot 5$ \\
\hline $\begin{array}{l}\text { RAN } \\
\text { RNA }\end{array}$ & & & & & & \\
\hline & 220 & 410,650 & 220 & 4 & 7 & $2 \cdot 2,2 \cdot 4,2 \cdot 5$ \\
\hline IBR & & & & & & \\
\hline IMO* & & & & & & \\
\hline ANS62 & $\cdots$ & $200,410,650$ & $\cdots$ & $\cdots$ & $7,8 \dagger$ & $\cdots$ \\
\hline $\left.\begin{array}{l}\text { SHO } \\
\text { SPO }\end{array}\right\}$ & $\cdots$ & 410,650 & $\cdots$ & $\cdots$ & 7 & $\cdots$ \\
\hline ITA & & $\ldots$ & 180 & $\ldots$ & & $2 \cdot 0$ \\
\hline RBL(Q) & 240 & 650 & 80 & 4 & 7 & $4 \cdot 5$ \\
\hline
\end{tabular}

DNA fragments used as probes (derived from the mec region of strain ANS46) are shown in fig. 1.

*Isolates IRO, IPE, and IHA gave hybridisation results identical to those of other members of this group when SmaI was used to digest the DNA; hybridisations were not done after HindIII treatment of the DNA for these three isolates.

$\uparrow 7-\mathrm{kb}$ band comprises two fragments of identical size.

identical, with fragments that hybridised with probes MA11 (one fragment), MA13 (two identical fragments) and MA14 (three fragments). The MSSA members of the Alfred group had only the band that hybridised with probe MA13. Isolate RAN had the same hybridisation pattern as the Alfred MRSA and MISA isolates. Isolate RNA had the same hybridisation pattern in the mec region as the Alfred isolates but, like strain ANS46, differed from the Alfred isolates in having four additional fragments showing homology with probe MA13. Strain ANS62, the methicillin-sensitive variant of strain ANS46, had no bands that hybridised with probes MA11 or MA14, while probe MA13 showed that homology to Tn554 existed in two identical fragments, remote from the mec region, and a fragment adjacent to the mec region.

The miscellaneous isolate $\operatorname{RBL}(\mathrm{Q})$ had the same HindIII fragment that hybridised with probe MA11 as was found in all the MRSA isolates; it also carried the single MA13-hybridising band corresponding to a remote copy of Tn554, and a further single fragment that hybridised with probe MA14. The other miscellaneous isolate, ITA, was the only isolate that showed homology only to probe MA14. Therefore, the molecular features of the mec region revealed by DNA hybridisation experiments reflected closely the divisions identified by RFLP analysis with SmaI (fig. 2).

The MRSA and MISA isolates of the Alfred group had an identical pattern of hybridising fragments (fig. 5), and a similar SmaI-generated RFLP pattern (not shown), to the Canberra type-II strain which was involved in an outbreak of MRSA in the two public hospitals in Canberra in 1989. The Canberra type-I strain from that study shared an identical pattern of HindIII fragments (fig. 5) with the ANS46/RNA group, but was shown to differ by comparison of RFLP patterns (not shown).

\section{Discussion}

In the past, MRSA isolates have occurred spasmodically at the Alfred Hospital, usually as persistent types with high levels of methicillin resistance. The present study involved an outbreak of infections caused by $S$. aureus isolates characterised by intermediate resistance to methicillin (MISA), and therefore difficult to detect by routine methods. The first of these isolates (IBR) was identified some 6 months before other members of the MISA group and, because of its genetic similarity to the other MISA isolates, was possibly the pioneer of the group.

Analysis of genomic RFLPs from SmaI digests of total DNA permits an estimate of genetic similarity. Fragment differences occur where a difference in sequence within one of the two DNA sequences compared results in loss or gain of a SmaI site. For instance, a comparison of the RFLPs of strains ANS46 and ANS62 (a strain derived by the deletion from strain ANS46 of DNA from the mec region that contains a SmaI site), showed that two fragments in strain ANS46 were replaced by one fragment in strain ANS62. ${ }^{11}$ A dendrogram, based on $p$ values derived from RFLP analysis, showed the clustering of $S$. aureus strains into types. ${ }^{6}$ Within a type, isolates showed changes in up to three fragments, which corresponded to a $p$ value of $0 \cdot 01 .^{6}$ Analysis of RFLPs in this study showed that there were only minor differences among the MISA isolates (four of the six were identical by this test), and between these and two MRSA isolates (strains RMA and RBR; the latter a 
secondary isolate, apparently a genetic variant of strain IBR). Two multi-resistant, but $\mathbf{M c}^{\mathrm{s}}$, isolates (strains SHO and SPO) were also part of this group on the basis of RFLP patterns. These MISA, MRSA and MSSA isolates together constituted the Alfred cluster.

DNA hybridisation analysis demonstrated that there was no detectable molecular difference between the MISA and MRSA isolates in this group, despite the large difference in expressed resistance to methicillin. Accordingly, the difference in resistance must be attributed to small undetected differences in the mec region, or in a part of the chromosome remote from the $m e c$ region. The regulatory $f e m A$ gene, located $>1000 \mathrm{~kb}$ from $m e c A,{ }^{20}$ is one possible candidate. The appearance of the fully-resistant strain RBR, in a culture of strain IBR grown in the presence of methicillin, suggests that MISA strains may give rise to MRSA variants in infected patients, or in circumstances where MISA types encounter significant concentrations of methicillin or similar antibiotics. In any event, the presence of the difficult-to-detect MISA type should be taken as an indication of potential cognate MRSA types; thus, care in the interpretation of resistance measurements, particularly those of marginal significance, is indicated.

The two MSSA isolates from the Alfred group had lost the mec gene and sequences to the right of mec in the chromosome, as shown by their failure to hybridise with probes MAll and MA14. They still carried sequences contained in probe MA13, but these were Tn554 $\left(\mathrm{Em}^{\mathrm{r}}\right)$ sequences located remote from the mec region $;{ }^{19}$ they appeared to have lost parts of the mec region, and thus were similar to strain ANS62, a laboratory-derived deletion mutant of strain ANS46 whose mec region has been mapped in detail. ${ }^{11,12}$ That the MSSA isolates represent natural deletion homologues of the MRSA and MISA types in the Alfred group seems likely; they were isolated in Nov. 1990 and Jan. 1991, well after the main group of MISA and MRSA types (Oct. 1989-July 1990). The simultaneous appearance of the MRSA strains and their MSSA deletion homologues in an MRSA outbreak has been observed in three instances over a 10-year period. ${ }^{21}$

As noted, the Alfred group of isolates had an identical hybridisation pattern, and a similar SmaIgenerated RFLP pattern, to the Canberra type-II group, which was involved in an outbreak of MRSA in 1989 in the two major public hospitals in Canberra.

\section{References}

1. Lacey RW, Kruczenyk SC. Epidemiology of antibiotic resistance in Staphylococcus aureus. I Antimicrob Chemother 1986; 18 Suppl C: 207-214.

2. Skurray RA, Rouch DA, Lyon BR et al. Multiresistant Staphylococcus aureus: genetics and evolution of epidemic Australian strains. J Antimicrob Chemother 1988; 21 Suppl C: $19-38$.

3. Gillespie MT, Lyon BR, Skurray RA. Typing of methicillinresistant Staphylococcus aureus by antibiotic resistance phenotypes. J Med Microbiol 1990; 31 : 57-64.

4. Vickery AM, Beard-Pegler MA, Stubbs E. Phage-typing patterns and lysogenicity of methicillin-resistant strains of
However, the Alfred group differed significantly from the earlier Melbourne lineage represented by strain ANS46. This was shown by the absence from the Alfred isolates of a copy of Tn554 in or near the mec region, and their sensitivity to $\mathrm{Hg}$ and $\mathrm{Tc}$, indicating that these resistance genes were also absent. The SmaI digestion patterns also separated the two Melbourne lineages. Accordingly, the Alfred and Canberra typeII groups may be representatives of a new lineage of MRSA/MISA, replacing older, though still extant, lineages represented by strain ANS46. The Alfred isolate RNA may be a modern representative of the older ANS46 lineage, as seems true of the Canberra type-I group described previously. ${ }^{6}$

Isolate RAN was interesting in having a mec region similar to that of the Alfred group, but chromosomal RFLPs which set it apart. It may be of a different chromosomal (i.e., clonal) background, with the Alfred type mec region inserted into a different chromosomal background following transfer by a phage or plasmid vector.

The other two isolates examined in this studystrains ITA and RBL(Q) - were confirmed to be different from the other MISA and MRSA isolates collected in the Alfred Hospital on the basis of their distinct RFLP patterns. Subsequent analysis has shown that strain ITA belongs to the same group as an MRSA type (representative strain R155) that has been found commonly in New Jersey, USA (unpublished results).

The use of RFLP analysis following digestion with rare-cutting endonucleases such as $S m a I$ offers a useful approach to the analysis of $S$. aureus populations, and might be used to identify more precisely the origins and spread of new and old clones of staphylococci. Thus, even without the analysis of the mec region described here, conclusions could be drawn about the overall similarities and differences between the groups of isolates shown in fig. 2. With simplified procedures between bacterial isolation and resolution of genomic fragments on PFGE, the approach described here for comparisons on the basis of RFLP similarities and differences could become a useful method for general clinical application.

This study was supported in part by the National Health and Medical Research Council of Australia. We thank Libby Viccars for excellent technical assistance and the Microbiology Diagnostic Unit at the University of Melbourne for phage typing.

Staphylococcus aureus from Sydney, Australia, 1965-85. J Med Microbiol 1986; 22 : 209-216.

5. Lacey RW, Grinsted J. Genetic analysis of methicillin-resistant strains of Staphylococcus aureus: evidence for their evolution from a single clone. J Med Microbiol 1973; 6: 511-526.

6. El-Adhami W, Roberts L, Vickery A, Inglis B, Gibbs A, Stewart PR. Epidemiological analysis of a methicillin-resistant Staphylococcus aureus outbreak using restriction fragment length polymorphisms of genomic DNA. J Gen Microbiol $1991 ; 137$ : 2713-2720.

7. Heineine N, Stewart PR. Physiological determination of methicillin resistance in Staphylococcus aureus: comparison of clinical and genetically derived isolates. $J$ Antimicrob Chemother 1986; 17 : 705-715. 
8. Matthews PR, Reed KC, Stewart PR. The cloning of chromosomal DNA associated with methicillin and other resistances in Staphylococcus aureus. J Gen Microbiol 1987; 133: 1919-1929.

9. Skinner S, Inglis B, Matthews PR, Stewart PR. Mercury and tetracycline resistance genes and flanking repeats associated with methicillin resistance on the chromosome of Staphylococcus aureus. Mol Microbiol 1988; 2: 289-292.

10. Inglis B, Matthews PR, Stewart PR. The expression in Staphylococcus aureus of cloned DNA encoding methicillin resistance. J Gen Microbiol 1988; 134: 1465-1469.

11. Inglis B, Matthews PR, Stewart PR. Induced deletions within a cluster of resistance genes in the mec region of the chromosome of Staphylococcus aureus. J Gen Microbiol 1990; 136: 2231-2239.

12. Dubin DT, Matthews PR, Chikramane SG, Stewart PR. Physical mapping of the $m e c$ region of an American methicillin-resistant Staphylococcus aureus strain. Antimicrob Agents Chemother 1991; 35: 1661-1665.

13. Franklin JC. Assessment of antibiotic-sensitive, intermediate or resistant status of bacteria by agar dilution. Med Lab Sci 1988; 45: 225-234.

14. Pattee P. Staphylococcus aureus. Genetic Maps 1987; 4: $148-154$.
15. Chu G, Vollrath D, Davis RW. Separation of large DNA molecules by contour-clamped homogeneous electric fields. Science 1986; 234 : 1582-1585.

16. Upholt WB. Estimation of DNA sequence divergence from comparison of restriction endonuclease digests. Nucleic Acids Res 1977; 4: 1257-1265.

17. Nei M, Li W-H. Mathematical model for studying genetic variation in terms of restriction endonucleases. Proc Natl Acad Sci USA 1979; 76: 5269-5273.

18. Hedges AJ. Principles of microbial taxonomy. In: Hawker LE, Linton AH (eds) Microorganisms: function form and environment. London, Edward Arnold. 1971 : 458-472.

19. Chikramane SG, Matthews PR, Noble WC, Stewart PR, Dubin DT. Tn554 inserts in methicillin-resistant Staphylococcus aureus from Australia and England: comparison with an American methicillin-resistant group. J Gen Microbiol 1991; 137 : 1303-1311.

20. Berger-Bächi B, Barberis-Maino L, Strässle, A, Kayser FH. Fem A, a host-mediated factor essential for methicillin resistance in Staphylococcus aureus: molecular cloning and characterization. Mol Gen Genet 1989; 219: 263-269.

21. Inglis B, El-Adhami W, Stewart PR. Methicillin-sensitive and methicillin-resistant homologues of Staphylococcus aureus occur together among clinical isolates. J Infect Dis 1993; in press. 